\title{
Inhibition of extracellular signal-regulated kinase activity by sorafenib increases sensitivity to DNR in K562 cells
}

\author{
RUO-ZHI XIAO ${ }^{1,2}$, CHENG-MING HE ${ }^{1,2}$, MU-JUN XIONG ${ }^{1,2}$, XING-XING RUAN ${ }^{1,2}$, \\ LI-LIN WANG ${ }^{1,2}$, YAN CHEN ${ }^{1,2}$ and DONG-JUN LIN ${ }^{1,2}$ \\ ${ }^{1}$ Department of Hematology, Third Affiliated Hospital, Sun Yat-sen University; \\ ${ }^{2}$ Sun Yat-sen Institute of Hematology, Guangzhou, Guangdong 510630, P.R. China
}

Received October 30, 2012; Accepted December 28, 2012

DOI: $10.3892 /$ or.2013.2331

\begin{abstract}
The mitogen-activated protein kinase (MAPK) pathway has a protective function on the management of hematologic malignancies. The aim of this study was to assess whether the induction of MAPK-mediated effects contributes to the therapeutic value of combination sorafenib and daunorubicin (DNR) treatment. Herein, we found that DNR increased phosphorylation of extracellular signal-regulated kinases (ERK1/2) in K562 cells. ERK1/2 activity was blocked by either the mitogen-induced extracellular kinase (MEK) inhibitor U0126 or a multi-kinase inhibitor sorafenib. Of note, sorafenib sensitized K562 to DNR by inhibiting proliferation and inducing apoptosis in a dose-dependent manner which was through blocking the RAF/MEK/ERK pathway. Moreover, K562 cells transfected with a constitutively active MEK2DD plasmid showed increasing $\mathrm{IC}_{50}$ values following DNR treatment compared with control cells. Combination of DNR with MEK inhibitor U0126 synergistically inhibited K562 cell growth. In conclusion, our results indicated that sorafenib sensitized K562 cells to DNR-induced cytotoxicity by downregulating $\mathrm{p}$-ERK1/2 expression. DNR in combination with sorafenib may represent a new and potential therapeutic strategy in treating acute leukemia with high p-ERK1/2 levels.
\end{abstract}

\section{Introduction}

DNA topoisomerase II inhibitors, such as daunorubicin (DNR), are potent antineoplastic agents widely used in the treatment of patients with leukemia, lymphoma and diverse solid tumor malignancies. They exert their function by introducing the formation of a stable complex between enzyme DNA topoisomerase II and DNA as well as by generating

Correspondence to: Professor Ruo-Zhi Xiao, Department of Hematology, Third Affiliated Hospital, Sun Yat-Sen University, 600 Tianhe Road, Guangzhou, Guangdong 510630, P.R. China E-mail: xiaorzh@126.com

Key words: sorafenib, daunorubicin, K562, apoptosis, survival, Raf/MEK/ERK pathway reactive oxygen species (ROS) (1). The introduction of doublestrand DNA breaks and alterations in the replication and transcription trigger apoptosis and cell death (2). However, the development of drug resistance in leukemia cells poses a major obstacle in the successful treatment of acute leukemia. It has been reported that overexpression of constitutively active Raf-1 and P-gp could form drug resistance to DNR, and the expression of the P-gp extrusion pump was regulated by the Ras/Raf/MEK/ERK pathway (3-5).

DNR can activate the Raf/MEK/ERK pathway via the protein kinase $\mathrm{C} \zeta(\mathrm{PKC} \zeta)$ pathway and combine with $\mathrm{MEK}$ inhibitor to enhance the antitumor activity (6). The constitutive activation of certain cellular signaling pathways contributes to tumor development and resistance to chemotherapy $(7,8)$. Kornblau et al confirmed that simultaneous activation of multiple signal transduction pathways conferred poor prognosis in acute myelogenous leukemia (9). Upon growth factor stimulation, Ras/Raf/MEK/ERK triggers a series of cascade events that govern cell transformation, differentiation, proliferation and survival (10-12). Approximately $30 \%$ of tumors harbor active mutants of the Ras oncoprotein, and a downstream effector of Ras, Raf, is also frequently mutated in tumors $(13,14)$. The active Ras/Raf/MEK/ERK kinase pathway inevitably accounts for a hallmark of malignant phenotypes: abnormal cell growth, invasion and angiogenesis (7). Therefore, interruption of the Raf/MEK/ERK cascade has become a primary target in acute leukemia therapy.

Sorafenib, an oral small molecular multi-kinase inhibitor, has been approved by the Food and Drug Administration (FDA) for the treatment of patients with renal cell carcinoma and hepatoma $(15,16)$. Sorafenib was initially identified as a RAF kinase inhibitor, and was found to be able to inhibit the MAPK pathway in multiple cancer cell lines. In human xenograft models, including ovarian, colon, lung, pancreatic and melanoma, sorafenib inhibited tumor growth through inhibition of either the MAPK signaling or angiogenesis $(17,18)$.

In order to reduce the p-ERK1/2 level induced by DNR and extend the anti-leukemia activity of DNR, we combined sorafenib with DNR, and explored the potent cellular and molecular effects in K562 and U937 cell lines. Our present study suggested that DNR in combination with sorafenib may represent a new and immediately available therapeutic approach to treat acute leukemia with activated ERK1/2. 


\section{Materials and methods}

Reagents and antibodies. Sorafenib (Bayer, Pittsburgh, PA, USA) was dissolved in dimethyl sulfoxide (DMSO) and stored at $-20^{\circ} \mathrm{C}$. DNR was purchased from Sigma-Aldrich (St. Louis, MO, USA). U0126 (Alexis, San Diego, CA, USA), a MEK1/2 inhibitor, was dissolved in DMSO with a final concentration of $20 \mu \mathrm{M}$. The antibodies of rabbit anti-ERK1/2, anti-phosphoERK1/2 $\left(\mathrm{Tyr}^{202} / \mathrm{Tyr}^{204}\right)$ were obtained from Cell Signaling Technologies (Beverly, MA, USA). DMRIE-C was purchased from Invitrogen (Carlsbad, CA, USA).

Cell culture. The leukemia cell lines K562 and U937, of myeloid origin, were obtained from the American Type Culture Collection (ATCC) and grown in RPMI-1640 medium supplemented with $10 \%$ fetal bovine serum, $100 \mu \mathrm{g} / \mathrm{ml}$ penicillin and $100 \mu \mathrm{g} / \mathrm{ml}$ streptomycin. Cells were cultured at $37^{\circ} \mathrm{C}$ in a humidified atmosphere containing $5 \% \mathrm{CO}_{2}$. Control cultures received an equivalent amount of DMSO only. Cells in logarithmic growth phase were used for further experiments.

Cell viability assay. Cell viability was assessed by MTT assay. Briefly, cells at $1 \times 10^{5} / \mathrm{ml}$ were treated with various concentrations of DNR in 96 -well plates for $24 \mathrm{~h}$ at $37^{\circ} \mathrm{C}$. Then, MTT working solution ( $5 \mathrm{mg} / \mathrm{ml}$ in PBS) was added to each well and cells were incubated for $4 \mathrm{~h}$. The water-insoluble formazan was formed during incubation and was solubilized by adding DMSO to each well. The amount of formazan was determined by measuring the absorbance at $490 \mathrm{~nm}$ using a multiwell plate reader (Microplate Reader; Bio-Rad, Hercules, CA, USA). Percent cell viability was calculated as cell viability of the experimental samples/cell viability of the control samples $\mathrm{x} 100$. At least three independent experiments were performed.

Assessment of apoptosis. Apoptotic cells were evaluated by Annexin V/PI staining, and, in some cases, they were verified by Hoechst 33258 and Wright Giemsa staining according to the protocol. For flow cytometry analysis, cells were treated with various concentrations of DNR, sorafenib alone or in combination for $48 \mathrm{~h}$. The cells were harvested for Annexin V-Alexa Fluor-488/PI staining. The stained cells were analyzed by a Becton Dickinson FACScan flow cytometer.

Generation of transfection cell lines. MEK2DD, pBABEpuro MEK2DD plasmid were gifts from the Liuq's laboratory (Sun Yat-sen Institute of Hematology, Guangzhou, China) and pEGFP-N3 vector was purchased from BD Biosciences Clontech (Bedford, MA, USA). The full-length MEK2DD cDNA was subcloned into vector pEGFP-N3.

For stable transfection, pEGFP-N3 vector was introduced into K562 cells using DMRIE-C reagent, according to the manufacturer's instructions. Two days later, the cells were screened by G418 at a concentration of $1,000 \mu \mathrm{g} / \mathrm{ml}$, and five days later using G418 at a concentration of $500 \mu \mathrm{g} / \mathrm{ml}$ for continuous screening. For transient transfection, MEK2 constitutive active form, MEK2DD plasmid was introduced into K562 cells directly by DMRIE-C, and $72 \mathrm{~h}$ later, the cells were exposed to different concentrations of DNR.
Western blot analysis. K562 cells were treated with various concentrations of sorafenib or DMSO (control) for 6,12 and $24 \mathrm{~h}$. Thereafter, the cells were collected and lysed in a lysis buffer (1\% Triton X-100; $50 \mathrm{mM}$ HEPES, pH 7.4; $150 \mathrm{mM}$ $\mathrm{NaCl} ; 1$ mM EGTA; $100 \mathrm{mM} \mathrm{NaF} ; 10 \mathrm{mM}$ sodium pyrophosphate; $1 \mathrm{mM} \mathrm{Na} \mathrm{VO}_{4} ; 10 \%$ glycerol; $1 \mathrm{mM}$ PMSF; $10 \mu \mathrm{g} / \mathrm{ml}$ leupeptin). The levels of phosphorylated and total ERK1/2 in cell lysates were determined by immunoblotting with the corresponding antibodies. Briefly, cell lysates (50 $\mu \mathrm{g}$ protein per well) were resolved by eletrophoresis on $10-12 \%$ sodium dodecyl sulfate-polyacrylamide gels (SDS-PAGE; Bio-Rad) and transferred to PVDF membranes. The membranes were first incubated in TBST $(50 \mathrm{mM}$ Tris- $\mathrm{HCl} ; 150 \mathrm{mM} \mathrm{NaCl}$; $0.05 \%$ Tween-20) containing 5\% non-fat dry milk for $1 \mathrm{~h}$ to block nonspecific protein binding; they were then washed with TBST three times, and incubated with primary antibody (1:1000 dilution) overnight at $4^{\circ} \mathrm{C}$. The next day, the PVDF membranes were washed with TBST three times, and incubated with HRP-conjugated secondary antibody (1:2500 dilution) for $1 \mathrm{~h}$ at room temperature. The membranes were then washed with TBST, and antibody binding was visualized with the use of a super chemiluminescence detection system.

Statistical analysis. Data are presented as means \pm SD. One-way ANOVA followed by Bonferroni multiple comparison was performed to assess the differences between two groups under multiple conditions. If the data failed the normality test, the Kruskal-Wallis one-way ANOVA on ranks was used. $\mathrm{P}<0.05$ was considered to indicate statistically significant differences. The interaction between DNR and sorafenib or U0126 was analyzed according to Jin's formula, determining whether the combination was additive or synergistic. Jin's formula was performed based on the following equation: $q=D_{1+2} /\left(D_{1}+D_{2}-\right.$ $D_{1} \times D_{2}$ ), where $D_{1+2}$ indicated the effect when cells were used in combination with drug 1 and 2 , and $\mathrm{D}_{1}, \mathrm{D}_{2}$ indicated the effect when used alone. The value of $q$ indicated synergism when $>1.15$, antagonism when $<0.85$, and additivity when located between 0.85 and 1.15 .

\section{Results}

K562 cells are less sensitive to DNR than U937 cells with high p-ERK1/2 levels. K562 and U937 cells were both exposed to DNR for $24 \mathrm{~h}$. The cytotoxic effects of DNR were determined by MTT assay. As shown in Fig. 1A and B, DNR inhibited cell proliferation in a dose-dependent manner. The $\mathrm{IC}_{10}$ values of DNR for K562 and U937 cells were $0.82 \pm 0.12 \mu \mathrm{g} / \mathrm{ml}$ and $0.055 \pm 0.011 \mu \mathrm{g} / \mathrm{ml}$, respectively. The antiproliferative effects of DNR on K562 were stronger than those on U937 cells. However, K562 cells were more sensitive to sorafenib than U937 cells (Fig. 1C). To investigate the reason why K562 and U937 cells had different reactions to DNR or sorafenib, the p-ERK1/2 levels were evaluated by western blot assay. We found that the p-ERK1/2 level of K562 cells was higher than that of U937 cells (Fig. 1D). In addition, cell lines were treated with combinations of these two agents at different doses but in a constant ratio (sorafenib to DNR: $4.0-16.0 \mu \mathrm{g} / \mathrm{ml}$ to $1.0 \mu \mathrm{g} / \mathrm{ml}$ in $\mathrm{K} 562$ cells, $4.0-16.0 \mu \mathrm{g} / \mathrm{ml}$ to $0.05 \mu \mathrm{g} / \mathrm{ml}$ in U937 cells, respectively). As shown in Fig. 2, the combination of sorafenib with DNR inhibited the growth of K562 and U937 cells in a 
A

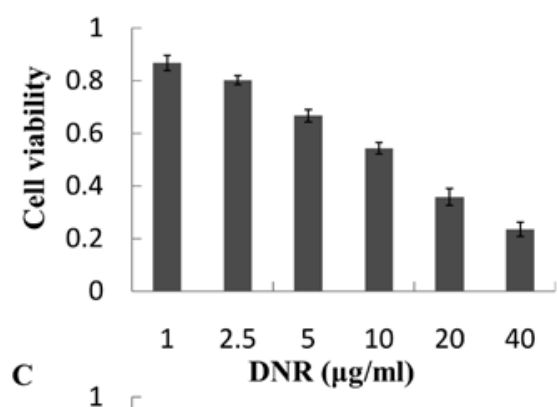

$\mathrm{C}$

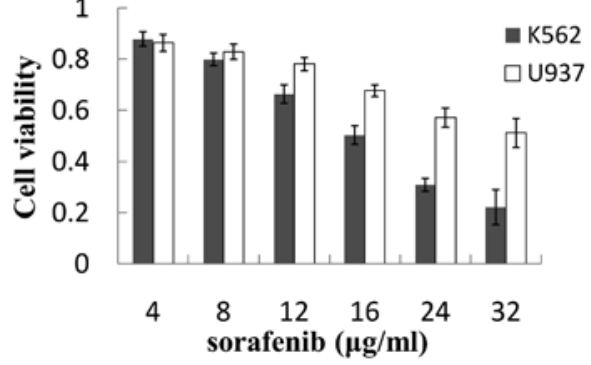

B

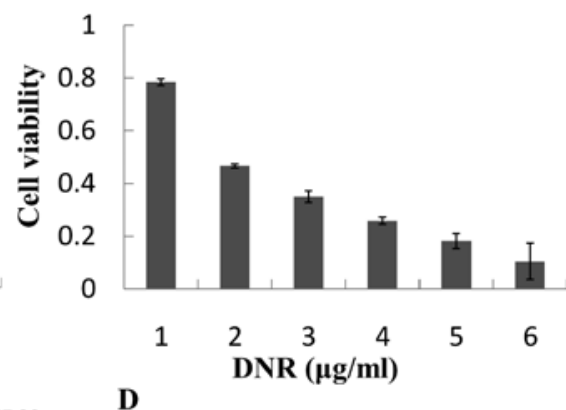

D

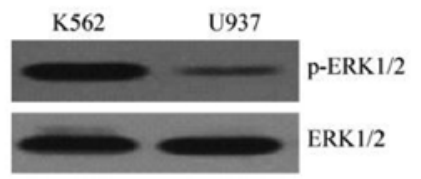

Figure 1. DNR or sorafenib inhibits the cell viability of K562 and U937 cells. (A and B) K562 and U937 cell lines were treated with different concentrations of DNR for $24 \mathrm{~h}$. MTT assay was performed. (C) The two cell lines were treated with 4-32 $\mu \mathrm{g} / \mathrm{ml}$ sorafenib for $24 \mathrm{~h}$ and cell proliferation was determined via an MTT assay. (D) The p-ERK1/2 level of K562 and U937 was tested by western blot assay. The bar represents means \pm SD of three independent experiments.

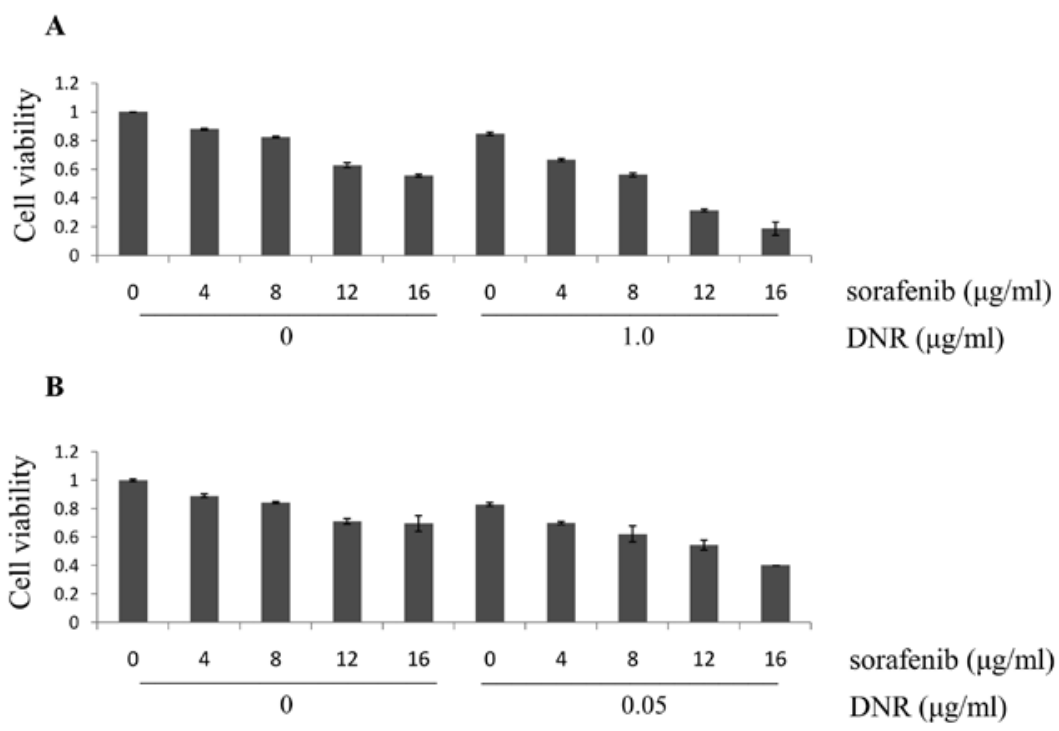

Figure 2. Combination effect of DNR and sorafenib on K562 and U937 cells. (A) K562 cells were treated with different concentrations of sorafenib (4.0-16.0 $\mu \mathrm{g} / \mathrm{ml}$ ) concomitantly with DNR at $1.0 \mu \mathrm{g} / \mathrm{ml}$ for $48 \mathrm{~h}$. (B) U937 cells were also exposed to sorafenib (4.0-16.0 $\mu \mathrm{g} / \mathrm{ml})$, DNR $(0.05 \mu \mathrm{g} / \mathrm{ml})$, and their combination, as indicated, for $48 \mathrm{~h}$. MTT assay was performed. The graph displays the means \pm SD of three independent experiments.

dose-dependent manner. Moreover, Jin's formula was used to determine synergy. At each dose level, the combined effects resulted in synergism $(\mathrm{q}>1.15)$. This indicates that the effects of the combination on cell viability are likely synergistic.

Sorafenib synergistically enhances the apoptotic effect of DNR on K562 cells. To assess whether combined treatment enhanced apoptosis, apoptotic analysis was conducted by Annexin V/PI, Wright-Giemsa and Hoechst 33258 staining on K562 cells treated with sorafenib, either alone or together with DNR for $48 \mathrm{~h}$. Flow cytometry showed that the combination of $16 \mu \mathrm{g} / \mathrm{ml}$ sorafenib with $1 \mu \mathrm{g} / \mathrm{ml}$ DNR in K562 cells resulted in apoptosis rates of $36.2 \%$, compared to sorafenib
(24.55\%) or DNR (2.67\%) alone (Fig. 3). According to Jin's method, sorafenib in combination with DNR had synergistic effects of apoptosis on K562 cells $(\mathrm{q}>1.15, \mathrm{p}<0.01)$. The morphological changes demonstrated by Wright-Giemsa and Hoechst 33258 staining also confirmed this conclusion. An apparent increase in the percentage of cells with typical chromatin condensation and fragmentation of nuclei was observed in cell cultures treated with the combination of sorafenib and DNR compared to either agent alone (Fig. 4A). As shown in Fig. 4B, marked morphological changes of cell apoptosis, such as cell shrinkage and nuclear condensation, were observed. These results suggest that sorafenib sensitizes K562 cells to DNR-induced apoptosis. 
A sorafenib $(\mu \mathrm{g} / \mathrm{ml})$

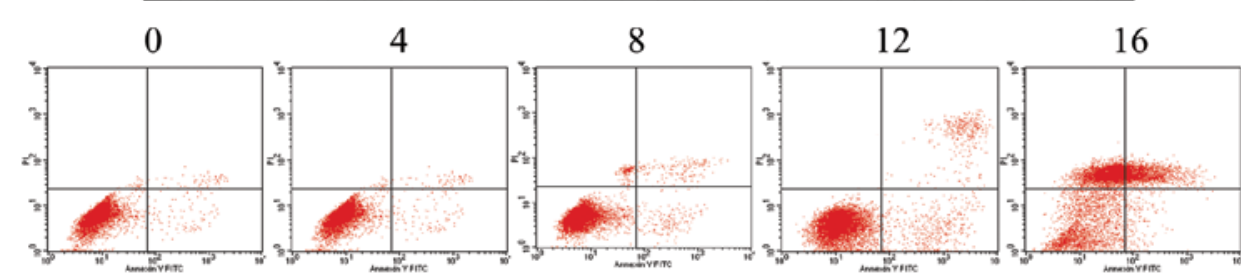

DNR

$(0 \mu \mathrm{g} / \mathrm{ml})$

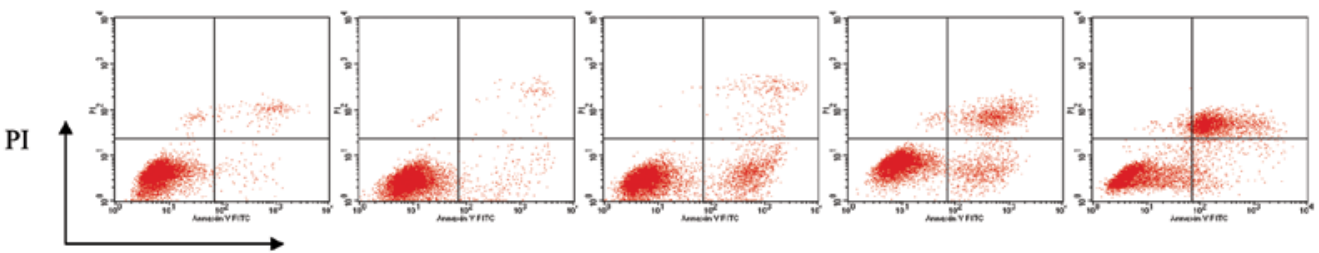

DNR

$(1 \mu \mathrm{g} / \mathrm{ml})$

Annexin $V$

B

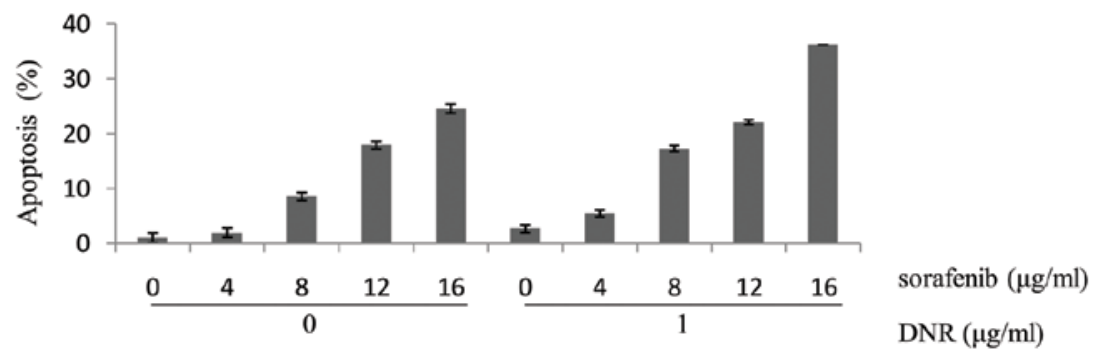

Figure 3. Combination of sorafenib and DNR induces apoptosis in K562 cells. (A) K562 cells were incubated with the indicated doses of sorafenib, DNR, or a combination of both for $48 \mathrm{~h}$ before staining with Annexin V-FITC and PI. The apoptosis was assessed by flow cytometry. (B) K562 cells were incubated for $48 \mathrm{~h}$ with the indicated doses of sorafenib and DNR, and the percentage of apoptotic cells was displayed. Results are expressed as a percentage of the vehicle-treated control \pm SD of three separate experiments.

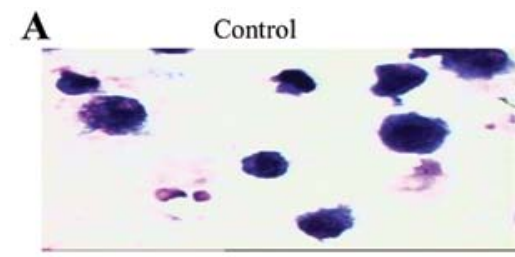

Sora $12.0 \mu \mathrm{g} / \mathrm{ml}$

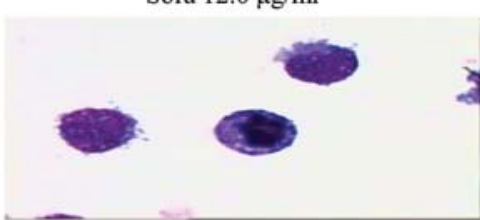

$\mathbf{B}$

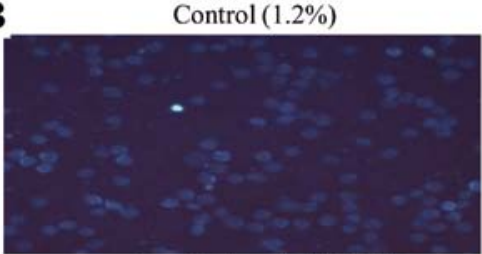

Sora $12.0 \mu \mathrm{g} / \mathrm{ml}(18.3 \%)$

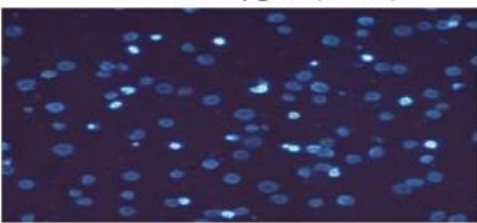

$\mathrm{DNR} 1.0 \mu \mathrm{g} / \mathrm{ml}$

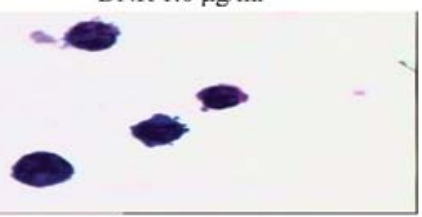

DNR $1.0 \mu \mathrm{g} / \mathrm{ml}+$ Sora $12.0 \mu \mathrm{g} / \mathrm{ml}$

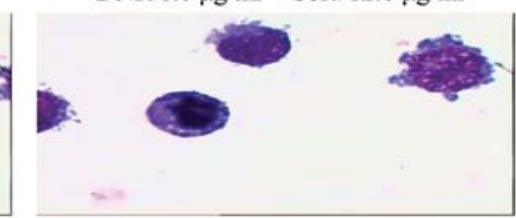

DNR $1.0 \mu \mathrm{g} / \mathrm{ml}(2.2 \%)$

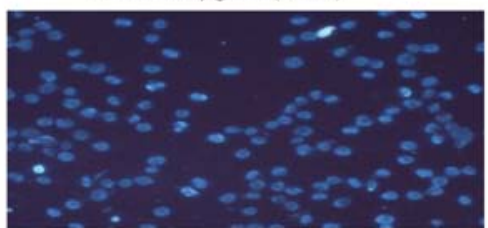

DNR $1.0 \mu \mathrm{g} / \mathrm{ml}+$ Sora $12.0 \mu \mathrm{g} / \mathrm{ml}(28.6 \%)$

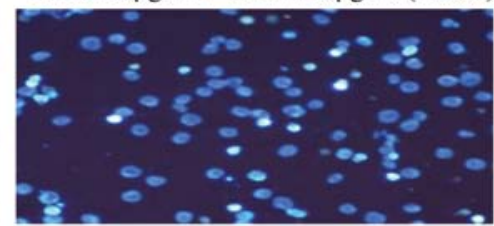

Figure 4. Typical morphological changes of apoptosis by Wright-Giemsa and Hoechst 33258 staining. Cells were cultured for $48 \mathrm{~h} \mathrm{with} 12 \mu \mathrm{g} / \mathrm{ml} \mathrm{sorafenib}$, $1 \mu \mathrm{g} / \mathrm{ml}$ DNR alone or in combination. (A) Cells were stained with Wright-Giemsa and then examined under a light microscope (magnification, x100). (B) Apoptosis observed by Hoechst 33258 staining (x40). Three independent experiments were performed with similar results, and representative data are shown. 

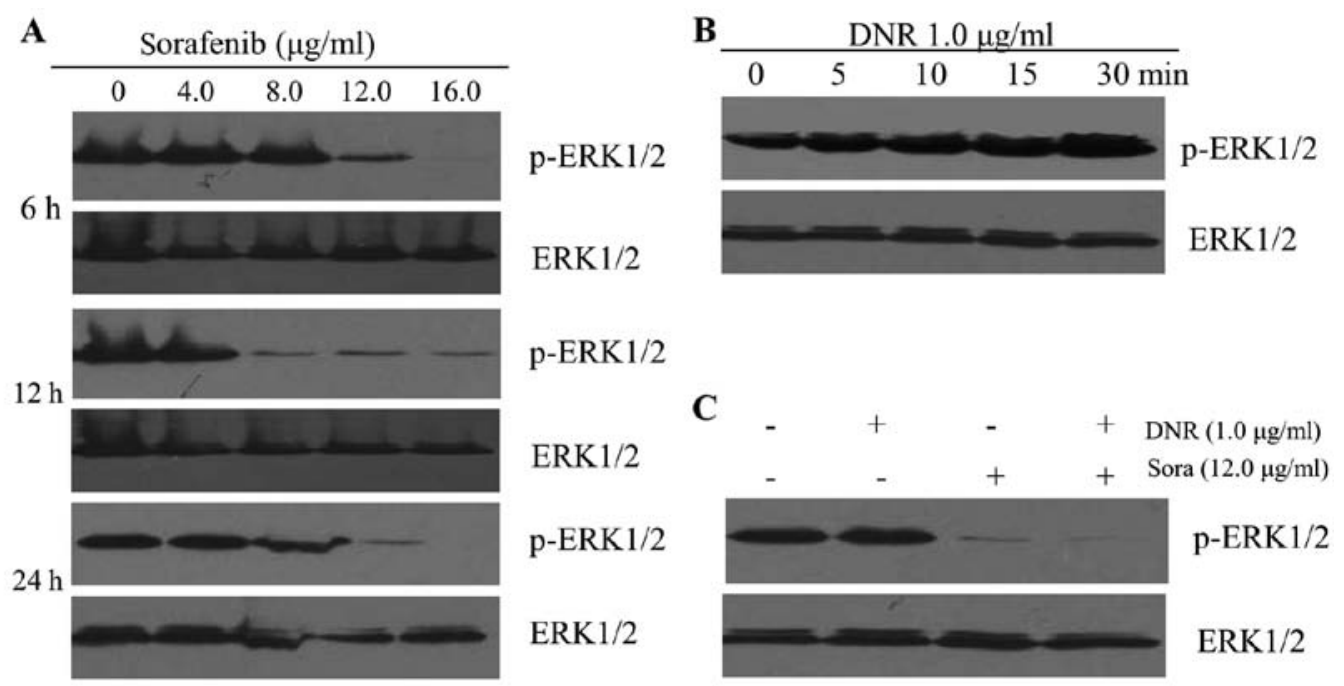

Figure 5. Effects of DNR and sorafenib on ERK1/2 phosphorylation. (A) K562 cells were treated with different concentration of sorafenib for 6, 12 and 24 h. (B) K562 cells were incubated with DNR for the indicated times. (C) K562 cells were exposed to sorafenib, DNR, or their combination, as indicated, for 24 h. The p-ERK1/2 protein levels were measured by western blot assay. Three independent experiments were performed for each of the above-mentioned experiments with similar results.
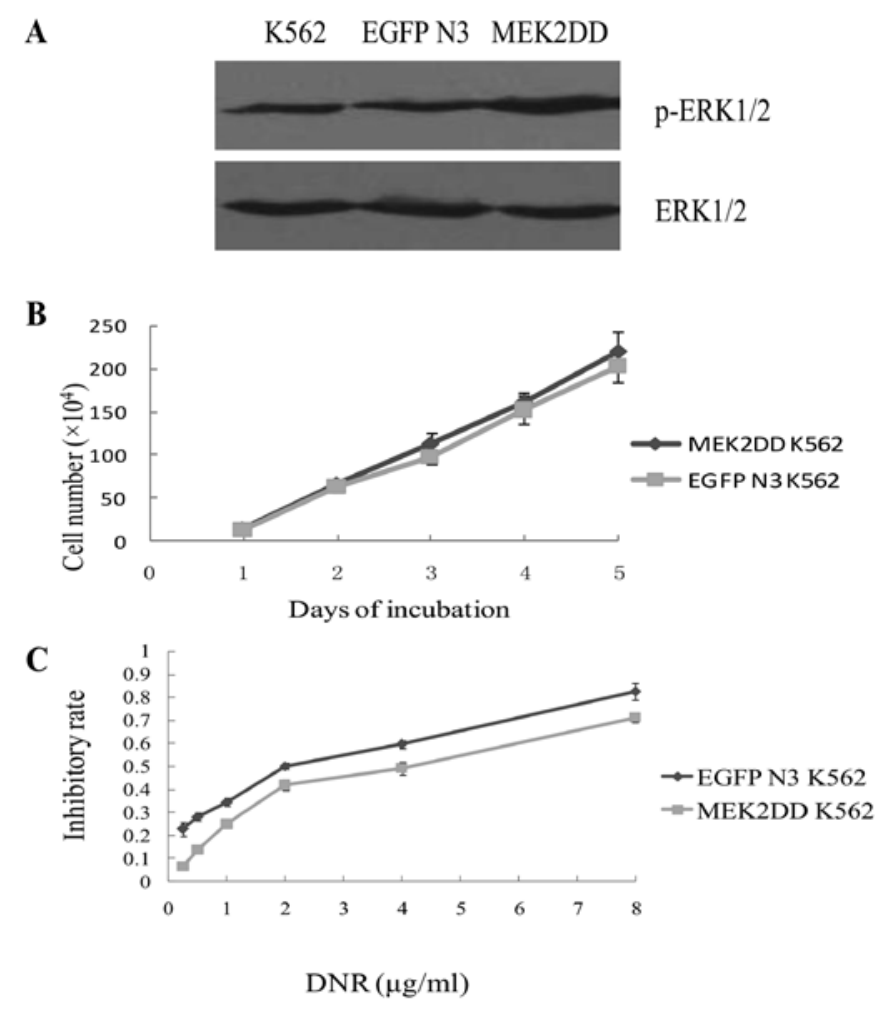

Figure 6. Upregulation of p-ERK1/2 levels with transfection attenuates the cytotoxic effect of DNR on K562 cells. (A) K562 cells were transfected with empty EGFP-N3 control or an active MEK2DD vector. (B) Cell populations of the MEK2DD-K562 and EGFP-K562 cells following incubation for the indicated days. (C) These two cells were simultaneously exposed to $0-8 \mu \mathrm{g} / \mathrm{ml}$ DNR for $48 \mathrm{~h}$, and the inhibitory rate was measured by MTT assay. Results are representative of three separate experiments.

Effects of sorafenib and DNR on ERK1/2 phosphorylation and activity. We found that sorafenib, a type of oral multi-kinase inhibitor which was recently approved by the FDA, suppressed p-ERK1/2 expression in a dose- and time-dependent manner on K562 cells. Sorafenib $(12 \mu \mathrm{g} / \mathrm{ml})$ downregulated the p-ERK1/2 level as early as $6 \mathrm{~h}$. After $24 \mathrm{~h}$, p-ERK1/2 expression was completely inhibited by sorafenib at $16 \mu \mathrm{g} / \mathrm{ml}$ (Fig. 5A). We then used antibody directed against phosphorylated forms of both ERK1 and ERK2, and found that incubation of K562 cells with $1.0 \mu \mathrm{g} / \mathrm{ml}$ DNR induced ERK1/2 activation, and ERK1/2 tyrosine phosphorylation was observed within $5 \mathrm{~min}$ and remained relatively stable for at least $30 \mathrm{~min}$ (Fig. 5B). The phosphorylation of ERK1/2 following treatment with DNR increased in a time-dependent manner. As shown in Fig. 5C, co-treatment with $12 \mu \mathrm{g} / \mathrm{ml}$ sorafenib and $1.0 \mu \mathrm{g} / \mathrm{ml}$ DNR caused the same attenuation of $\mathrm{p}-\mathrm{ERK} 1 / 2$ protein levels as treatment with sorafenib alone.

Upregulation of p-ERK1/2 levels in K562 cells attenuates the cytotoxic effect of DNR. To determine whether the observed upregulation of p-ERK1/2 could reduce the cytotoxic effect of DNR on K562 cells, we transfected K562 cells with empty EGFP-N3 control or an active MEK2DD vector. The p-ERK1/2 level after K562 cells transfected with MEK2DD vector was higher than control cells, as shown in Fig. 6A. However, there was no significant difference in the growth rate between these two types of transfected cells ( $p>0.05$ ) (Fig. 6B). Subsequently, K562 cells expressing empty vector or a MEK2DD vector encoding construct were exposed to increasing concentrations of DNR for $48 \mathrm{~h}$. MTT assay showed that $\mathrm{IC}_{50}(3.33 \pm 0.2 \mu \mathrm{g} / \mathrm{ml})$ of DNR on MEK2DD K562 was higher than that on EGFP$\mathrm{K} 562(1.71 \pm 0.14 \mu \mathrm{g} / \mathrm{ml})(\mathrm{p}<0.01)$.

MEK1/2 inhibitor U0126 sensitizes K562 cells to DNR. To evaluate whether blocking of the RAF/MEK/ERK pathway could increase the efficacy of DNR to inhibit leukemia cells, U0126 (MEK1/2 inhibitor) in combination with DNR was used. p-ERK1/2 expression was completely downregulated after incubation with $20 \mu \mathrm{M}$ U0126 for $24 \mathrm{~h}$ in K562 and EGFP-K562 cells (Fig. 7A). Subsequently, K562 cells were exposed to DNR $(0.25-8.0 \mu \mathrm{g} / \mathrm{ml})$ in combination with $20 \mu \mathrm{M}$ $\mathrm{U} 0126$ simultaneously for $48 \mathrm{~h}$. As expected, the inhibitory rate 


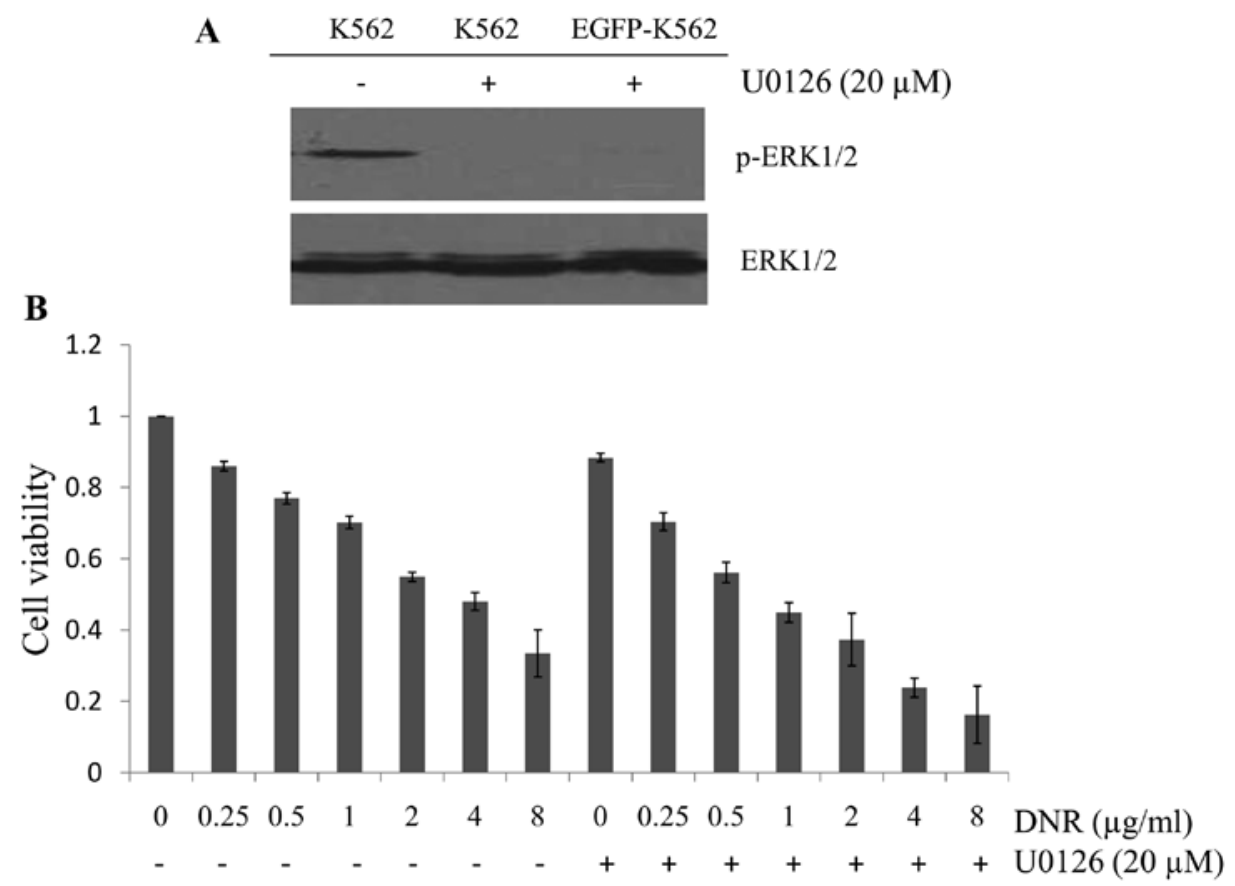

Figure 7. MEK1/2 inhibitor U0126 sensitizes K562 cells to DNR. (A) K562, EGFP-K562 cells were treated with DMSO as control or $20 \mu \mathrm{M}$ U0126 for $24 \mathrm{~h}$, and the p-ERK1/2 level was measured by western blot assay. (B) K562 cells were cultured with different doses of DNR $(0.25-8.0 \mu \mathrm{g} / \mathrm{ml}) \mathrm{concomitantly} \mathrm{with}$ $20 \mu \mathrm{M} \mathrm{U} 0126$ for $48 \mathrm{~h}$. MTT assay was performed. Results are representative of three separate experiments, and representative data are shown.

of the combination was higher than any concentration of DNR alone. Jin's formula was used to determine synergy, and the results were consistent. The value q of each drug concentration was $>1.15(\mathrm{p}<0.01)$, thereby suggesting that downregulation of the p-ERK1/2 level could enhance sensitivity to DNR in K562 cells.

\section{Discussion}

In the present study, we demonstrated that sorafenib effectively downregulated p-ERK1/2 levels and that this activity directly contributed to the sensitization of K562 cells to DNR. DNR represents one of the major antitumor agents widely used in the treatment of acute myeloid leukemia. Cytotoxicity induced by DNR is related to DNA damage due to intercalations of the drug and its interaction with nuclear topoisomerase II (19). DNR has been reported to induce apoptosis in myeloid leukemia cell lines (20). However, whether apoptosis simply reflects DNA lesions or represents an independent cytotoxic mechanism triggered by a specific signaling pathway remains controversial (21).

We found that incubation of K562 cells with $1.0 \mu \mathrm{g} / \mathrm{ml}$ DNR induced ERK1/2 activation, and p44/p42 ERK1/2 tyrosine phosphorylation was observed within $5 \mathrm{~min}$ and remained relatively stable for at least $30 \mathrm{~min}$. Mas et al confirmed that the activation of ERK1/2 by DNR was relevant to PKC (6). Han et al first reported that DNR induced cytoprotective autophagy by activation of ERK in myeloid leukemia cells (22). ERK1/2 is a member of the mitogen-activated protein kinase (MAPK) family. The classical MAPK module consists of a Raf-1 kinase, mitogen-induced extracellular kinase (MEK), and extracellular regulated kinase (ERK). The majority of the water-soluble growth factors, which regulate the growth, proliferation and differentiation of normal and transformed cells, exert at least part of their effects by signaling through the highly conserved Ras/Raf/MEK/ERK pathway. A cascade of kinase activation occurs after the cognate receptor ligated. Therefore, the Raf/MEK/ERK pathway can govern drug resistance, apoptosis and sensitivity to target therapy $(23,24)$. Some studies have suggested that this signal transduction pathway may be involved in the regulation of several aspects of drug resistance. For instance, expression of the P-gp extrusion pump is regulated by the Ras/Raf/MEK/ERK pathway (5).

Sorafenib is an orally active multi-kinase inhibitor which was originally developed as an inhibitor of Raf-1. However, it has been subsequently shown to inhibit multiple other kinases, including platelet-derived growth factor $\beta$, vascular endothelial growth factor receptor 2 and 3, and FMS-like tyrosine kinase 3 (FLT3) (17). It has been used in combination with several anticancer drugs and has shown marked antitumor activity $(25,26)$. In order to improve the antitumor effect and slow down the formation of drug resistance, we combined sorafenib with DNR. Consequently, the combination of sorafenib with DNR resulted in the inhibition of proliferation and induction of apoptosis in a dose-dependent manner on K562 cells. The combination effect could be synergistic according to Jin's formula. The value $\mathrm{q}$ of each drug concentration was more than $1.15(\mathrm{p}<0.01)$. Apoptotic effects were measured by flow cytometry, Hoechst 33258 and Wright Giemsa staining, and all results were consistent. The present study demonstrated that sorafenib suppressed p-ERK1/2 expression in a dose- and time-dependent manner in K562 cells. Furthermore, sorafenib alone or in combination with DNR suppressed the p-ERK1/2 expression with no difference.

To investigate whether upregulating the p-ERK1/2 level may reduce the cytotoxity of DNR, K562 cells which transfected 
with empty vector or a MEK2DD vector encoding construct were exposed to increasing concentrations of DNR for $48 \mathrm{~h}$. We found that K562 cells transfected with a constitutively active MEK2DD plasmid showed increasing $\mathrm{IC}_{50}$ values following DNR treatment compared with control cells. These results confirmed that high p-ERK1/2 levels could reduce the antitumor effect of DNR on K562 cells. Conversely, suppression of the p-ERK1/2 expression with U0126 enhanced DNR-induced apoptosis in K562 cells.

Raf-1/ERK activation contributes to cell survival when drug concentrations are reduced due to low-dose schedules, pharmacokinetic alterations, or altered bio-distribution. In this regard, we speculated that constitutive MAPK activation, as evidenced in fresh leukemia cells, may significantly alter DNR cytotoxicity in clinical settings $(27,28)$. For this reason, co-treatment of sorafenib and DNR in patients with leukemia is very efficient and effective. Thus, the combination mechanism between sorafenib and DNR should be further studied in primary leukemia specimens and xenograft models.

In summary, this study indicated that the combination of DNR and sorafenib contributed to a synergistic anti-leukemia activity in vitro and ERK1/2 could be a potential target for pharmacologic manipulation to improve DNR-induced cytotoxity on leukemia cells.

\section{References}

1. Thornalley PJ and Dodd NJ: Free radical production from normal and adriamycin-treated rat cardiac sarcosomes. Biochem Pharmacol 34: 669-674, 1985.

2. Pommier Y: DNA topoisomerase I and II in cancer chemotherapy: update and perspectives. Cancer Chemother Pharmacol 32: 103-108, 1993

3. Weinstein-Oppenheimer CR, Henríquez-Roldán CF, Davis JM, et al: Role of the Raf signal transduction cascade in the in vitro resistance to the anticancer drug doxorubicin. Clin Cancer Res 7: 2898-2907, 2001.

4. Kim SH, Lee SH, Kwak NH, Kang CD and Chung BS: Effects of the activated Raf protein kinase on the human multidrug resistance 1 (MDR1) gene promoter. Cancer Lett 98: 199-205, 1996.

5. Cornwell MM and Smith DE: A signal transduction pathway for activation of the mdrl promoter involves the proto-oncogene c-raf kinase. J Biol Chem 268: 15347-15350, 1993.

6. Mas VM,Hernandez H,PloI, et al: Protein kinase Czeta mediated Raf-1/extracellular-regulated kinase activation by daunorubicin. Blood 101: 1543-1550, 2003.

7. Hanahan D and Weinberg RA: The hallmarks of cancer. Cell 100: 57-70, 2000.

8. Vogelstein B and Kinzler KW: Cancer genes and the pathways they control. Nat Med 10: 789-799, 2004.

9. Kornblau SM, Womble M, Qiu YH, et al: Simultaneous activation of multiple signal transduction pathways confers poor prognosis in acute myelogenous leukemia. Blood 108: 2358-2365, 2006.
10. Kolch W: Coordinating ERK/MAPK signalling through scaffolds and inhibitors. Nat Rev Mol Cell Biol 6: 827-837, 2005.

11. Yoon S and Seger R: The extracellular signal-regulated kinase: multiple substrates regulate diverse cellular functions. Growth Factors 24: 21-44, 2006.

12. McCubrey JA, Steelman LS, Chappell WH, et al: Roles of the Raf/MEK/ERK pathway in cell growth, malignant transformation and drug resistance. Biochim Biophys Acta 1773: 1263-1284, 2007.

13. Giehl K: Oncogenic Ras in tumour progression and metastasis. Biol Chem 386: 193-205, 2005.

14. Thompson $\mathrm{N}$ and Lyons J: Recent progress in targeting the Raf/ MEK/ERK pathway with inhibitors in cancer drug discovery. Curr Opin Pharmacol 5: 350-356, 2005.

15. Escudier B, Eisen T, Stadler WM, et al: Sorafenib in advanced clear-cell renal-cell carcinoma. N Engl J Med 356: 125-134, 2007.

16. Strumberg D, Clark JW, Awada A, et al: Safety, pharmacokinetics, and preliminary antitumor activity of sorafenib: a review of four phase I trials in patients with advanced refractory solid tumors. Oncologist 12: 426-437, 2007.

17. Wilhelm SM, Carter C, Tang L, et al: BAY 43-9006 exhibits broad spectrum oral antitumor activity and targets the RAF/ MEK/ERK pathway and receptor tyrosine kinases involved in tumor progression and angiogenesis. Cancer Res 64: 7099-7109, 2004.

18. Wilhelm S, Carter C, Lynch M, et al: Discovery and development of sorafenib: a multikinase inhibitor for treating cancer. Nat Rev Drug Discov 5: 835-844, 2006.

19. Cummings J, Anderson L, Willmott N and Smyth JF: The molecular pharmacology of doxorubicin in vivo. Eur J Cancer 27: 532-535, 1991.

20. Quillet-Mary A, Mansat V, Duchayne E, et al: Daunorubicininduced internucleosomal DNA fragmentation in acute myeloid cell lines. Leukemia 10: 417-425, 1996.

21. Hannun YA: Functions of ceramide in coordinating cellular responses to stress. Science 274: 1855-1861, 1996.

22. Han W, Sun J, Feng L, et al: Autophagy inhibition enhances daunorubicin-induced apoptosis in K562 cells. PLoS One 6: e28491, 2011.

23. Weinstein-Oppenheimer CR, Blalock BL, Steelman LS, et al: The Raf signal transduction cascade as a target for chemotherapeutic intervention in growth factor responsive tumors. Pharmacol Ther 88: 229-279, 2000

24. Abrams SL, Steelman LS, Shelton JG, et al: The Raf/MEK/ERK pathway can govern drug resistance, apoptosis and sensitivity to targeted therapy. Cell Cycle 9: 1781-1791, 2010.

25. Dasmahapatra G, Yerram N, Dai Y, Dent P and Grant S: Synergistic interactions between vorinostat and sorafenib in chronic myelogenous leukemia cells involve Mcl-1 and p21CIP1 down-regulation. Clin Cancer Res 13: 4280-4290, 2007.

26. Yu C, Friday BB, Lai JP, et al: Cytotoxic synergy between the multikinase inhibitor sorafenib and the proteasome inhibitor bortezomib in vitro: induction of apoptosis through Akt and c-Jun $\mathrm{NH}_{2}$-terminal kinase pathways. Mol Cancer Ther 5: 2378-2387, 2006.

27. Towatari M, Iida $\mathrm{H}$, Tanimoto $\mathrm{M}$, et al: Constitutive activation of mitogen-activated protein kinase pathway in acute leukemia cells. Leukemia 11: 479-484, 1997.

28. Laurent $G$ and Jaffrézou JP: Signaling pathways activated by daunorubicin. Blood 98: 913-924, 2001. 